\title{
Algumas experiências acadêmicas em habitação de interesse social na região sudeste do Brasil: regularização fundiária em municípios entre as regiões metropolitanas de Campinas e São Paulo
}

\author{
Glacir Teresinha Fricke* \\ Jairo Bastidas** \\ Sergio Quaglia**
}

\section{Resumo}

O déficit habitacional brasileiro é de mais de 8 milhões de moradias, cifra alarmante para um pais em desenvolvimento. Estudou-se Itatiba e Amparo, localizadas entre Campinas e São Paulo. Este trabalho apresenta o relato de duas experiências desenvolvidas pelo CEUr (Universidade São Francisco): O "Projeto Casa e o "Projeto HabitAmparo". Estas intervenções possibilitam vários esclarecimentos: evidenciam os descompassos dos processos e convertem-se em alicerces conceituais para sua aplicação em contextos análogos. Inferiu-se uma metodologia que subsidia os processos de regularização fundiária e melhoramento de habitação. Concluiu-se, que, a atuação das prefeituras e a participação comunitária são decisivas na solução de problemas associados às questões de Habitação. Por outra parte, os estudos revelam o impacto das ferramentas advindas do Estatuto da Cidade. Também, não é possível negligenciar o marco criado para a elaboração do Plano Nacional de Habitação, que proporciona subsídios prospectivos para a abordagem criteriosa desta seara do conhecimento.

\section{Palavras chave}

Regularização fundiária; Segregação espacial; Interdisciplinaridade; Habitação.

\section{Resumen: Algunas experiencias académicas en materia de vivienda social en el sureste de Brasil: regularización del suelo en los municipios entre las regiones me- tropolitana de Campinas y São Paulo}

El déficit habitacional en Brasil es de más de 8 millones de viviendas, una cifra alarmante para un país en desarrollo. Se estudiaron Itatiba y Amparo, ubicadas entre Campinas y São Paulo. Este trabajo presenta la historia de dos experiências llevadas a cabo por el CEUR (Universidad San Francisco): El "Proyecto Casa" y el "Proyecto HabitAmparo". Estas intervenciones permiten varias aclaraciones: evidencian los desajustes de los procesos y se convierten en bases conceptuales para su aplicación en situaciones similares. Se estructuró una metodología que sustenta los procesos de regularización del suelo y mejoramiento de viviendas. Se concluye que las acciones de los gobiernos locales y la participación comunitaria son cruciales en la solución de problemas relacionados con asuntos de vivienda. Por otro lado, los estudios muestran el impacto de las herramientas provenientes del Estatuto de la Ciudad. Además, no podemos pasar por alto el marco de referencia creado para la Elaboración del Plan Nacional de Vivienda, que proporciona apoyo prospectivo para el enfoque riguroso de esta línea de conocimiento.

\section{Palabras clave}

Regularización del suelo; Segregación espacial; Interdisciplinaridad; Vivienda.

\footnotetext{
Recibido 20/09/2010; aceptado: 24/10/2010

* Datos de contacto: Glacir Teresinha Fricke. Curso de Arquitetura e Urbanismo. Universidade São Francisco - Itatiba, SP / Pontifícia Universidade Católica PUCMinas - Poços de Caldas, MG. E-mail: glacir.fricke@saofrancisco.edu.br.

** Datos de contacto: Jairo Bastidas, Universidade de Brasília - UnB, Brasil / Universidade São Francisco - Itatiba. Rua Alexandre Rodrigues Barbosa №. 45. Bairro Centro. Itatiba, SP, Brazil. CEP 06140-000. E-mail: jairobg@gmail.com.

*** Datos de contacto: Sergio Quaglia. Universidade São Francisco - USF, Brasil. Rua Alexandre Rodrigues Barbosa No. 45. Bairro Centro. Itatiba, SP, Brazil. CEP 06140-000.E-mail: slqsadv@gmail.com.
} 


\section{Abstract: Some academic experiences in social housing in southeastern Brazil: land regularization in the metropolitan areas between cities of Campinas and São Paulo}

The housing deficit in Brazil is of more than 8 million homes, an alarming figure for a developing country. We studied Itatiba and Amparo, located between Campinas and São Paulo, Brazil. This work presents the story of two experiments carried out by CEUR (São Francisco University): The "House" Project and the "HabitAmparo" Project. These interventions lead to various explanations by showing the disproportion of the processes which are converted into conceptual foundations for application in similar situations. A methodology is structured that underpins the process of regularization and improvement of housing. It is concluded that actions of local governments and community participation are crucial in solving problems associated with housing issues. On the other hand, the studies show the impact of the tools originating from the City Statute. Furthermore, we should not overlook the point of reference created with the drafting of the National Housing Plan, which provides subsidies for the strict approach of this line of research.

\section{Key words}

Agrarian Regularization; Spatial Segregation; Interdisciplinarity; Social Housing.

\section{Introdução}

Em pleno começo do século XXI o Brasil é um dos países que paulatinamente está se afastando do grupo das nações subdesenvolvidas. Mas este rótulo não significa necessariamente que o território brasileiro esteja norteado pelas condições desenvolvimentistas do primeiro mundo. De modo contraposto, o solo descoberto pelos lusitanos ainda está imerso num contexto de infindáveis desigualdades em diferentes áreas, que representam obscuras incertezas para sua população. Dentre essas um dos assuntos estruturais é o que diz respeito à questão habitacional.

Este trabalho versa sobre a prioridade que representa este quesito, em especial, sobre a regularização fundiária. Para melhor entendimento das informações relatadas, o presente trabalho está dividido em 4 partes. Na primeira parte foi elaborado um sucinto arcabouço teórico que pretende corroborar a pertinência da temática de assuntos associados à habitação de interesse social. No item dois são explanados os contextos dos municípios de Itatiba e Amparo e seus assentamentos objetos de estudo. No item três são citados os procedimentos metodológicos, as análises e os resultados nos quais a intervenção foi alicerçada.
No item quatro são aduzidas as principais convergências e divergências encontradas nas assessorias interdisciplinares dos dois processos analisados. Na parte final, à guisa de conclusão, frisaram-se algumas considerações que sintetizam a importância das discussões sobre habitação no território brasileiro.

\section{$\mathrm{O}$ quadro da irregularidade e o direito à moradia}

A cidade é um espaço onde comparecem múltiplas realidades, caracterizadas por marcantes desigualdades e contrastes. $\mathrm{Na}$ atualidade, estas nuances não estão necessariamente atreladas à dimensão ou escala dos assentamentos urbanos, podendo ser encontradas tanto em regiões metropolitanas quanto em cidades de menor porte (Bastidas, 2003).

Segundo o IBGE, atualmente, no território brasileiro mais de $80 \%$ da população se concentra nos núcleos urbanos. O crescimento acelerado e desordenado das cidades deixa em evidência um dos mais graves problemas de habitação das últimas décadas. Este quadro não é apenas fruto das incipientes políticas habitacionais, mas também da falta de opções satisfatórias e accessíveis do mercado imobiliário (Maricato, 1996; Alfonsin, 1997). 
Destarte, as pessoas são obrigadas a conviver em situação de exclusão espacial e precariedade social. Em resposta a estas assertivas a população mais carente tem sido pressionada a apelar a vários mecanismos que forneçam soluções reais de moradia e reivindiquem a verdadeira função social da terra. ${ }^{2}$

Segundo o Banco Mundial 70\% das unidades habitacionais que são produzidas nos países subdesenvolvidos são ilegais. Alfonsin (2006) afirma que entre 30 a $50 \%$ das propriedades no território brasileiro ocupam de forma irregular o espaço urbano. Diante do cenário de crise generalizada de moradia, existe uma proliferação de diferentes maneiras de ocupação irregular. As formas de ilegalidade mais comuns dizem respeito a acesso ao solo e construção informal de moradia (Fernandes, 1998). As circunstancias elencadas contradizem o artigo 6 da Constituição da República Federativa do Brasil que contempla o direito à moradia digna ${ }^{3}$ como direito social.

No intuito de evitar o crescimento deste panorama muitos municípios incentivam programas relativamente recentes visando a regularização de assentamentos precários e irregulares. Cronologicamente, este movimento iniciou-se quando na década de 1990 vários municípios organizaram programas de regularização fundiária, mas seu grande equívoco foi carecer da devida estruturação, isto é, não estiveram ancorados a uma lei federal de desenvolvimento urbano (Rolnik, 1997). Abordada deste modo, os efeitos foram insubstanciais e pouco alentadores.

Mas nos últimos anos pela intermediação do Estatuto da Cidade (Lei no 10.257 de 2001) esta si-

\footnotetext{
2 É preciso enfatizar que alguns indivíduos dos setores da sociedade que ostentam maiores recursos econômicos, também se valem de meios igualmente irregulares para a ocupação do solo urbano.

${ }^{3}$ A definição de moradia digna abrange: instalações sanitárias adequadas para a habitabilidade atendidas por serviços públicos essenciais como: água potável, esgoto, energia, iluminação, coleta de lixo, pavimentação, transporte e com acesso a equipamentos sociais básicos de interesse coletivo.
}

tuação mudou. O Estatuto mune aos municípios de um instrumental para implementar uma política urbana (Rolnik, 2004). Antes de caracterizá-lo vale a pena salientar que para a legislação brasileira, amparada na noção civilista do direito de propriedade individual e irrestrito, unicamente $o$ registro do imóvel em cartório é constitutivo de propriedade (Fernandes, 2002; Rolnik, 2004).

Os instrumentos que o Estatuto da Cidade criou para resolver problemas advindos da irregularidade fundiária no Brasil são: a) usucapião especial de imóvel urbano (individual ou coletiva); b) concessão de direito real de uso (individual ou coletiva); c) zonas especiais de interesse social; d) concessão especial de uso para fins de moradia (individual ou coletiva) (Fernandes, 2002). Em maior ou menor grau, todas estas medidas induzem o desenvolvimento urbano.

No contexto atual, perante o crescimento dos quadros de ilegalidade no espaço urbano, o poder público dos municípios tem se inclinado por aderir a três modos de Regularização Fundiária: a) como regularização jurídica dos lotes; b) como urbanização do assentamento c) como regularização urbanística. Acredita-se que esta última forma talvez seja a mais eficiente e abrangente para atingir resultados, pois fornece maiores possibilidades na hora de adequar as áreas ilegalmente ocupadas com a legislação urbanística e pondera, ao mesmo tempo, a necessidade de que a legislação seja mais condescendente a fim de buscar uma melhor interação na cidade (Alfonsin, 2006).

Por outra parte, o Ministério das Cidades alerta que para viabilizar a reposta à moradia popular é indispensável pensar também no entendimento do problema habitacional a partir do "déficit habitacional e a inadequação de moradias". Deste ponto de vista, estas feições nos fornecem subsídios no sentido de que é prioritário observar ao déficit por reposição e melhoria do estoque de moradias, pois neste cenário estão inscritas 
muitas das moradias em condições de precariedade no Brasil (Pereira et al., apud Ministério das cidades, 2005) Assim, este último parágrafo elucida a outra vertente do problema.

\section{Contexto geral}

Pelo geral, a resposta ao problema de moradia ou melhoramento dos assentamentos existentes apenas está subscrita às grandes áreas urbanas, especialmente, as regiões metropolitanas. Isto é decorrência que possuem diretrizes de planejamento e execução de políticas. Este panorama pouco tem se transformado nos anos recentes.

Entretanto, a aprovação do Estatuto da Cidade (Lei no 10.257 de 2001) simultaneamente ao Programa Nacional de Apoio à Regularização Fundiária Sustentável desenvolvido em 2003 são apontados como uma das estratégias a serem adotadas para a viabilização do combate ao déficit habitacional. Esta operacionalização permite a participação de cursos, faculdades, universidades ou mesmo associações de classe que atuam na área do urbanismo como prestadores de assistência técnica acessível e de qualidade (Fernandes, in Fernandes e Alfonsin, 2004).

O projeto CASA -Itatiba- e HABITAMPARO Amparo-, objetos de estudo deste artigo, se acoplam nesse contexto para possibilitar que os moradores do assentamento San Francisco e do Jaguari, respectivamente, possam evadir a insegurança que produz a ilegalidade e informalidade. As parcerias foram, estabelecidas entre as Prefeituras dessas duas cidades e a Universidade São Francisco.

É preciso salientar que, em função da abordagem inédita deste trabalho, são precárias as fontes bibliográficas extensas. Esclarecidos estes pontos preliminares, nos próximos itens nos debruçaremos diante dos assuntos relativos às intervenções em si. A apresentação do trabalho obedecerá a uma descrição, segundo a cronologia das atua- ções em cada lugar, isto é, primeiro Itatiba e na seqüência Amparo. De modo posterior, tentou-se articular as questões relevantes da realidade analisada dos assentamentos. Em primeiro lugar, será fornecido um quadro geral dos municípios e a caracterização morfológica dos bairros analisados.

\section{Os municípios de Itatiba e Amparo}

Itatiba é um dos 19 municípios que integram a Região Metropolitana de Campinas -cuja área territorial ocupa $3.348 \mathrm{~km}^{2}$, o que corresponde a 0,04\% da superfície brasileira e a 1,3\% do território paulista (Figura 1). Segundo os dados do Censo de 2000 do IBGE, a população de tal Região compreende 2,3 milhões de habitantes, o equivalente a $1,40 \%$ da população nacional e a $6,3 \%$ da estadual. O município conta, atualmente, com cerca de 100 mil habitantes. O município possui uma área de $325 \mathrm{~km}^{2}$ e representa $0,13 \%$ da área do Estado de São Paulo. É possível afirmar que tem uma área urbana pequena, diferente de outros municípios da região, sendo $26,12 \mathrm{~km}^{2}$, menor que $10 \%$ e uma área rural de 298,88 km². Está dividido em 79 bairros, sendo que desses 18 são considerados loteamentos irregulares ou clandestinos.

Amparo é um dos 645 municípios do Estado de São Paulo (Figura 1). O município pertence à microregião que leva o mesmo nome, que por sua vez está inserida na mesorregião de Campinas. $\mathrm{Na}$ atualidade é um dos 11 municípios paulistas considerados Estância Hidromineral. Segundo dados censitários de 2000 (IBGE), a cidade de Amparo abriga uma população de 60.404 habitantes, sendo que 43.157 (aproximadamente 72\%) moram na área urbana.

A organização administrativa desta cidade abrange 60 bairros totalmente constituídos e distribuídos nos seus $446.009 \mathrm{~km}^{2}$ de área. Em 1999, Amparo possuía 23 loteamentos irregulares, cifra que aumentou para 36 loteamentos em 2006. Calcula-se que, atualmente, cerca de 8000 imóveis estão em situação de irregularidade. Nessas áreas vivem 
em condições precárias aproximadamente mais de 10.000 pessoas. Observe-se que a cobertura dos serviços públicos prestados pelas concessionárias atinge apenas $60 \%$ dos domicílios.

Os municípios arrolados têm a particularidade de possuir um tamanho de população similares. Identifica-se que sofrem dos processos de informalidade e ilegalidade, referidos nos parágrafos precedentes, e tem como denominador comum uma localização estratégica. Isto é, ficam distanciados a escassos quilômetros das regiões metropolitanas de São Paulo e Campinas. Por esta condição, a área destes municípios é passível de ser vista também como alternativa de subsidio para a solução de moradia de áreas em expansão.

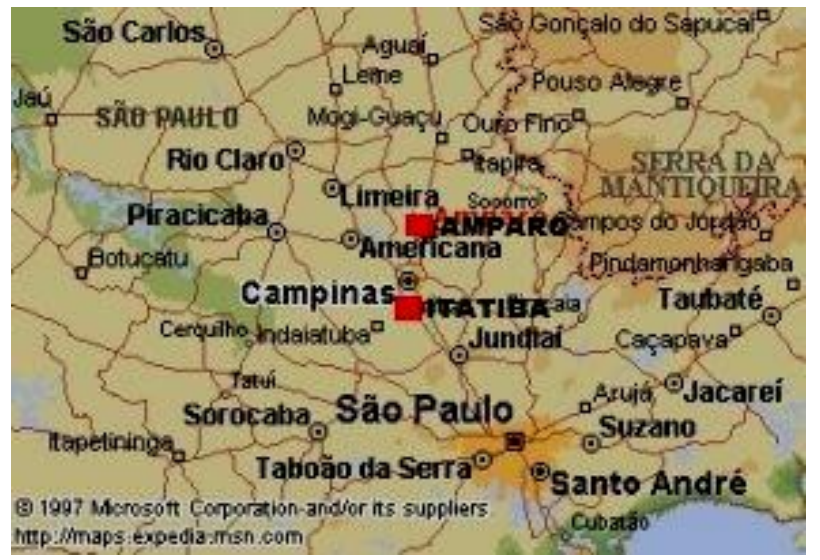

Figura 1: Localização das cidades de Itatiba e Amparo. <http://phyzweb.hypermart.net/amparo/amparop4.htm>. (Accesado 28/08/2010).

\section{Os loteamentos}

O bairro San Francisco, objeto de estudo do projeto CASA, foi implantado numa área intermediária entre o centro e as regiões perimetrais da cidade de Itatiba (Figura 2). Esta posição privilegiada permite inferir a facilidade de acesso e deslocamento de seus moradores aos diferentes equipamentos e infra-estrutura quase completa da cidade.

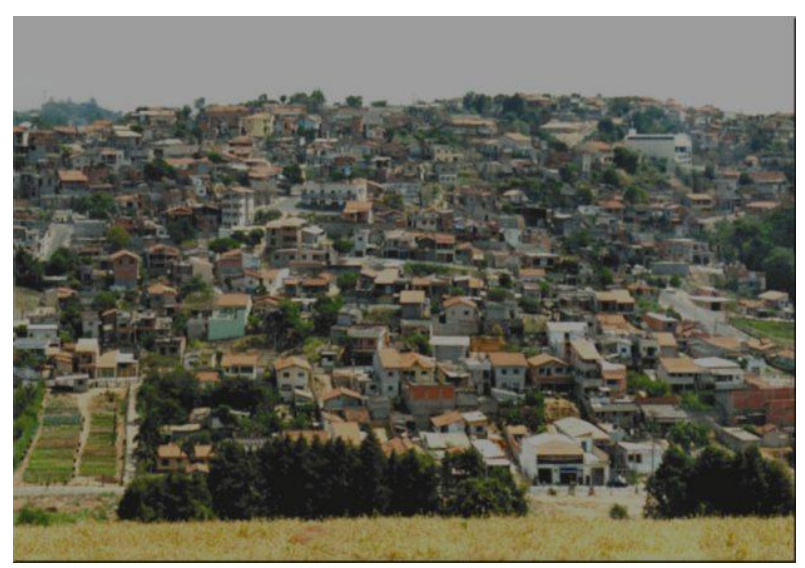

Figura 2: Vista do bairro San Francisco, Itatiba, SP, Brasil. Fonte: Arquivo Prefeitura de Itatiba.

$O$ assentamento Jaguari, analisado pelo projeto HABITAMPARO, está localizado a uma distância de 23,50 km do centro da cidade de Amparo (Figura 3). Sua paradoxal localização (próximo ao município de Morungaba) suscita uma série de implicações, pois sugere a utilização dessa localidade especialmente para o acesso de serviços públicos como: saúde, educação, comércio, cultura, recreação, lazer, etc.

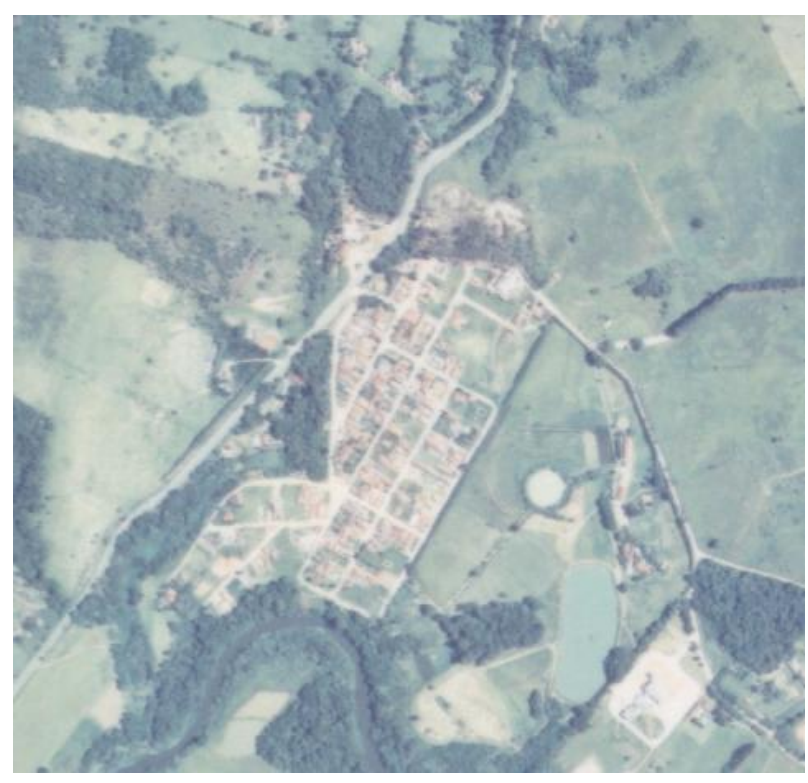

Figura 3: Aerofoto do bairro Jaguary, Amparo, SP, Brasil. Fonte: Arquivo Prefeitura de Itatiba.

Grosso modo, a evolução urbana dos bairros mencionados obedece à efetivação da ocupação antes de sua consolidação e aprovação junto às Prefeituras. Paralelamente, evidenciaram-se vendas irregulares e contínuas dos lotes. Algumas até hoje são motivo de discórdia. Esta dinâmica da 
ocupação, caminhando nos limiares entre o aparentemente legal e o ilegal sugere um curso, ao mesmo tempo, atípico e irreversível. Os problemas se agravaram quando a variável abandono e descaso administrativo tomaram conta na decada dos 80.

\section{Caracterização espacial dos bairros San Francisco e Jaguari}

Para uma descrição mais ponderada da situação atual dos assentamentos apelamos à metodologia das categorias morfológicas estruturais de Trieb e Schmidt (1980), citados por Kohlsdorf (1996). Optou-se por utilizar apenas uma das seis categorias, condizentes com os objetivos propostos, a saber:

a) Categoria planta baixa: a estrutura interna do espaço construído.

Planta Baixa (Itatiba / San Francisco): Tipo de malha. A malha urbana conformada por 29 quarteirões parte de um princípio de organização orgânica, o traçado foi rebatido num lote com forma acidentada e de grande declividade (Figura 4). Possui atributos como: assimetria, medidas aleatórias, predominância de linhas curvas com poucos elementos de composição. Esta estrutura se assemelha tangencialmente às tradicionais configurações de favela no Brasil. Tipo de parcelamento. A subdivisão interna dos quarteirões é balizada pela clássica divisão racionalista, sendo que comparecem múltiplas medidas de lotes. Relação de cheios e vazios. Há predominância de áreas ocupadas ao invés de áreas livres: públicas (ruas) e particulares (pátios), isto é, a taxa de ocupação é alta. A maioria das casas oscila entre térrea e dois pavimentos.

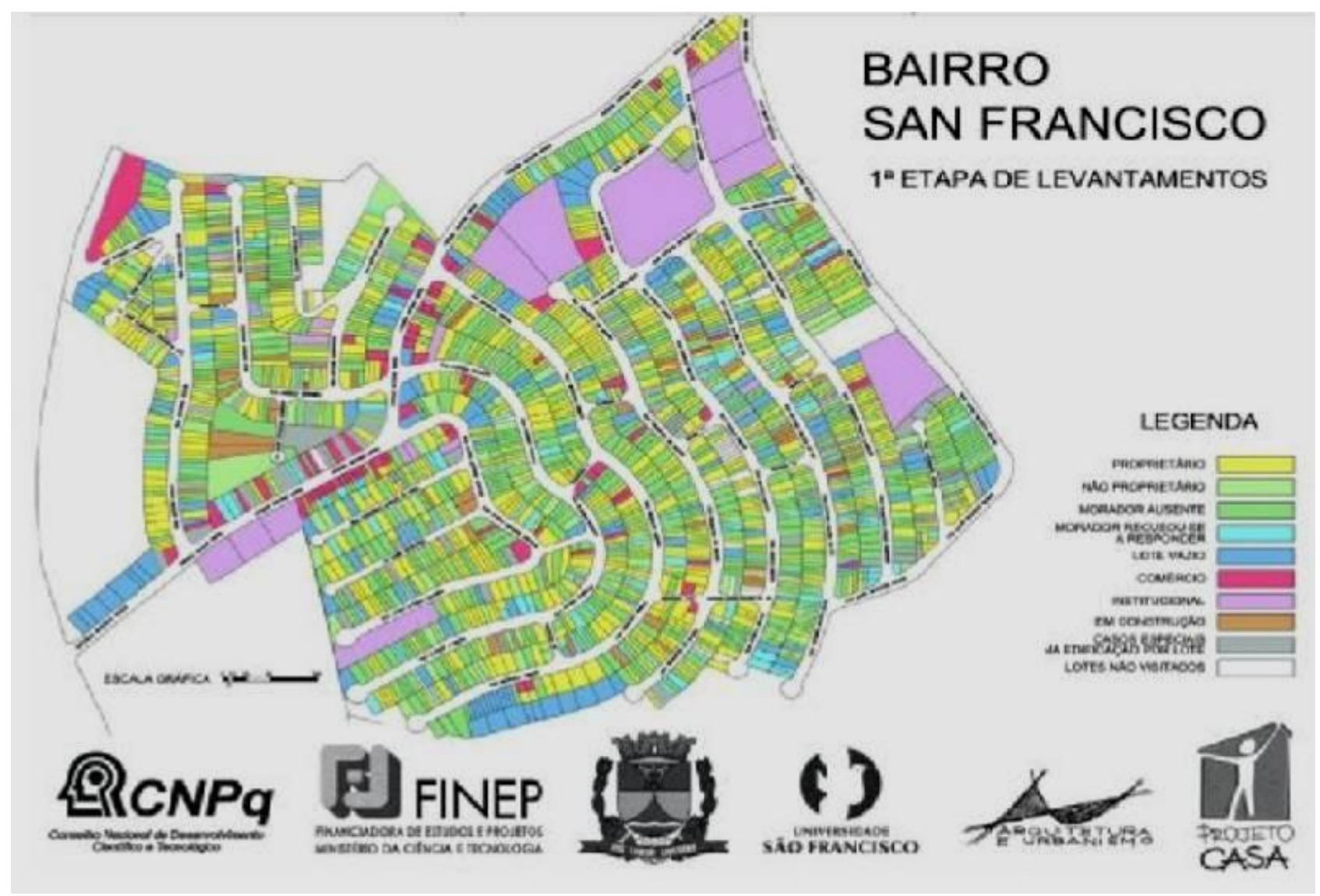

Figura 4: Planta urbana do bairro San Francisco, Itatiba. Fonte: Elaboração própria. 
Planta Baixa (Amparo/Jaguari): Tipo de malha. O traçado com 15 quarteirões obedece a princípios racionalistas, a malha está implantada num lote que possui forma irregular, onde se evidencia sua formação a partir de leis geométricas primárias (Figura 5). Possui constantes atributos como: simetria, paralelismo, predominância de linhas retas e poucos elementos de composição. Estas feições denotam que no empreendimento houve certo tipo de planejamento, diferente de algumas favelas que obedecem a princípios irregulares e labirínti- cos. Tipo de parcelamento. A subdivisão dos quarteirões é com formas regulares, sendo que os modelos mórficos predominantes são os lotes de dimen-sões $12 \times 25 \mathrm{~m}$ e $6 \times 25 \mathrm{~m}$. Relação de cheios e vazios. Neste quesito, verifica-se a predominância de áreas livres: públicas (ruas) e particulares (pátios) sobre as áreas ocupadas pelas edificações (taxa de ocupação baixa). A maioria das construções é térrea, situação que favorece a sensação de permeabilidade e as condições de luminosidade.

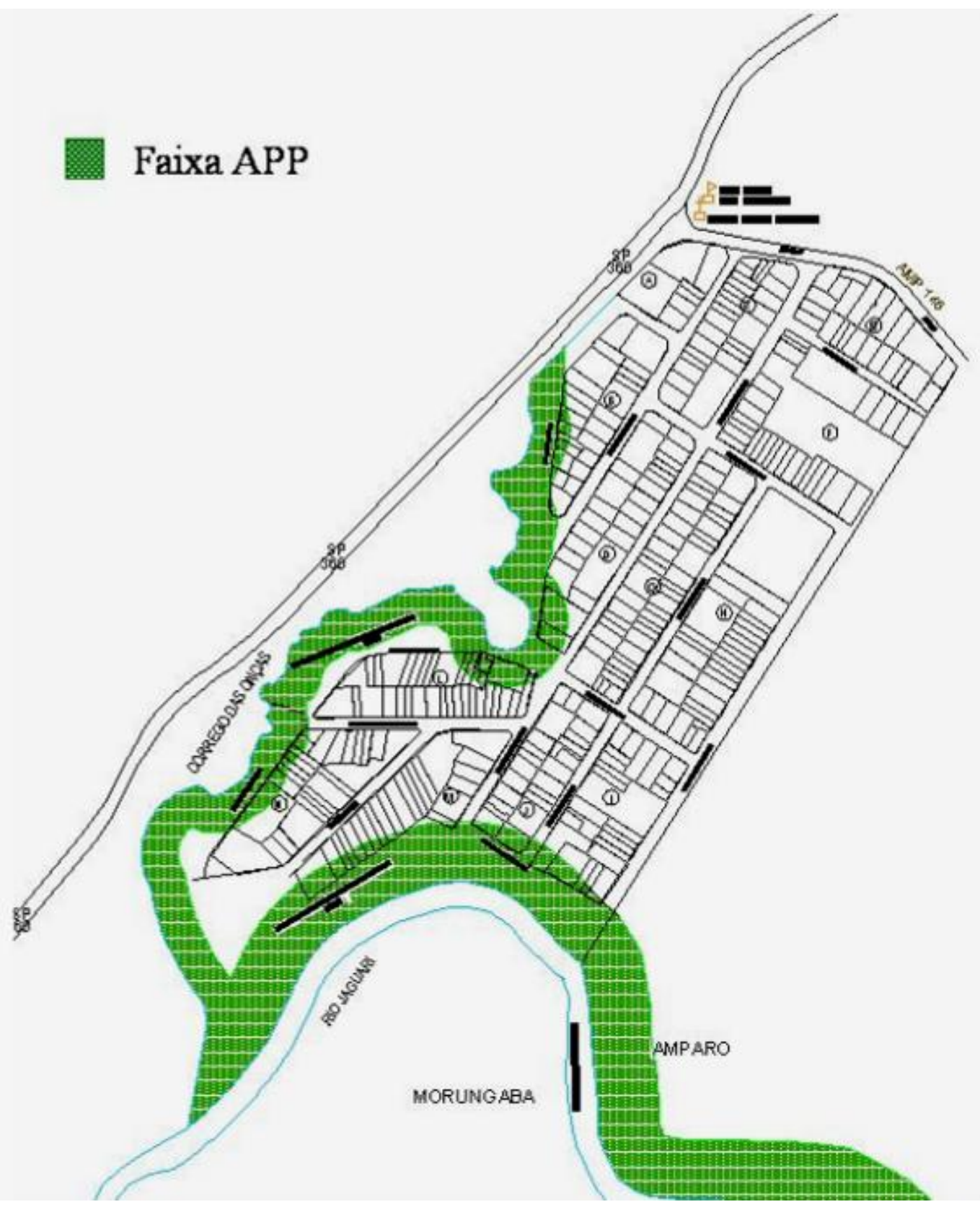

Figura 5: Planta urbana do bairro Jaguari, Amparo. Fonte: Elaboração própria. 
Referidos estes aspectos é necessário mencionar que a principal discrepância dos objetos de análise corresponde a sua escala urbana e quantidade de propriedades. O bairro San Francisco quase quintuplica ao loteamento de Amparo, isto é, o primeiro possui 1.745 e o segundo 342. Esta condição acarretou maiores dificuldades por questões operacionais, em especial, no que diz respeito ao investimento de tempo nos levantamentos e materialização das informações.

\section{Metodologia}

Optou-se pela execução dos projetos CASA e HABITAMPARO em várias etapas metodológicas que, a sua vez, se converteram em princípios norteadores destas experiências: a) aproximação; b) levantamentos socioeconômicos e arquitetônicos; c) tramitação jurídica d) implementação de programas sócio-educativos.

\section{Etapa de aproximação}

A formalização das parcerias entre a prefeitura de Itatiba, a FINEP ${ }^{4}$, bem como a parceria junto à prefeitura de Amparo, ambas com a Universidade São Francisco foi possível no período compreendido entre 2004 e 2007, respectivamente. No projeto CASA, com duração de dois anos, participaram os cursos de Arquitetura e de Direito do Câmpus de Itatiba. Já o projeto HABITAMPARO, que registrou uma vigência de três anos contou, além dos cursos de Arquitetura e Urbanismo e Direito, com a participação do Curso de Pedagogia, para o desenvolvimento dos Projetos Sociais.

Uma vez consolidadas as circunstâncias administrativas do acordo e definido o caráter das intervenções pactuou-se de modo unânime que era

\footnotetext{
4 "A FINEP atua em consonância com a política do Ministério da Ciência e Tecnologia (MCT), em estreita articulação com o Conselho Nacional de Desenvolvimento Científico e Tecnológico (CNPq). Enquanto o CNPq apóia prioritariamente pessoas físicas, por meio de bolsas e auxílios, a FINEP apóia ações de CT\&l de instituições públicas e privadas". $<$ http://www.finep.gov.br/o_que_e_a_finep/formas_atuacao.asp ?codSessaoOqueeFINEP=3>. (Acessado 28/08/2010).
}

impreterível o envolvimento da comunidade beneficiada, ao longo de todo o processo. A participação comunitária é fundamental, pois legitima os compromissos assumidos e, ao mesmo tempo, estabelece regras e prazos para o cumprimento das metas traçadas.

\section{Etapa de Levantamentos}

O trabalho de campo foi acertado de modo periódico. Metodologicamente apelou-se a um reconhecimento visual preliminar do parcelamento com o objetivo de conferir alguns dados indiretos (gráficos e escritos) para, de maneira posterior, coletar as informações individualizadas das unidades residenciais e dos lotes.

Esta fase do trabalho teve duas atividades principais: a) o levantamento de questões cadastrais sobre a população residente; e b) o levantamento arquitetônico do assentamento. A primeira ação subsidiou-se numa entrevista semi-estruturada com tópicos diferenciados e respostas pontuais, acertada com a Prefeitura, direcionada ao levantamento de dados quantitativos e diversos elementos relativos à habitabilidade das unidades familiares. Adicionalmente, recolheu-se a documentação para comprovação da propriedade de cada imóvel. A atividade de levantamento arquitetônico foi realizada de maneira tradicional, isto é, apelando à medição das casas e, imediatamente, transferindo as informações para desenhos em papel sulfite. Esta atividade subsidiou-se também em registros fotográficos. Visando a mensuração e agilização de trabalhos posteriores os dados coletados foram sistematizados em bases de dados e programas de desenho por computador. As plantas arquitetônicas digitalizadas de cada propriedade foi um dos produtos entregue à comunidade.

\section{Etapa de tramitação jurídica}

Para a regularização fundiária do loteamento a ocorrência desta fase é posterior à fase de levantamentos. Nesta etapa, o projeto analisa a docu- 
mentação e, se necessário, solicita outras informações adicionais que facilitem o processo de legalização junto ao Poder Judiciário. Criou-se o "kit judicial" que será o material que permitiu a judicialização. Destarte, baseados em uma avaliação criteriosa dos moradores e do local decidiu-se pela elaboração de uma proposta de aplicação de um ou vários dos instrumentos criados para a regularização fundiária.

\section{Etapa de implementação de programas sócio-educativos}

As necessidades derivaram das questões detectadas nos questionários, assim como das solicitações específicas das Prefeituras e das constatações da equipe técnica na área de estudo. Os programas abrangem formações que possibilitam o desenvolvimento individual (geração de renda, educação) e coletivo (ambiental) dos atores do projeto. Entretanto, um passo precedente é a consolidação e/ou fortalecimento da organização comunitária.

É necessário mencionar que a coordenação de todas as fases foi realizada pelas equipes Técnicas Administrativas das Prefeituras dos municípios de Itatiba e Amparo, os professores ${ }^{5}$ e técnicos ${ }^{6}$ da Universidade São Francisco. Os levantamentos foram executados pelos estagiários ${ }^{7}$ dos cursos

5 Além dos autores também participaram os seguintes docentes: Andrea Buchidid Loewen, Cláudia Maria Lima Ribeiro, Renata Baesso Pereira, Miriam de Lourdes Noronha Motta Melo, Armando Lopes Moreno Junior, Alencar de Melo Junior, Erci Belgini, Maria de Fátima Luknajenko e Camila d'Ottaviano.

6 Os técnicos envolvidos foram: Alexandre Torricelli, Marcus Massak, Priscila Meireles e André Penteado Tramontin.

7 Participaram os seguintes discentes: Alan Nascimento Neto, Christiane Arruda Rolfsen, Daniel Maciel, Danilo Araes Franco Lima, Dirceu da Silva Daiera, Emily Campolongo Ordine, Fernanda Aparecida de Souza, lara Franco Rizzi, Jussara Theodoro da Silva, Karina Vedovello da Costa, Leandro Aparecido Melo NunesMara Rúbia Golo Ferreira, Fabiana Matuoka, Mônica Pires Farinha, Silvia Oliveira Ledo, Érica Viviane Messias, Guilherme Sichler Suzan, Marília Toledo, Murilo Soldeira Silva, Renata Matsumoto Bárbara Oriani, Bianca Atique, Marília Toledo, Bárbara Puccineli e Maria Guadalupe Alvarez Zavalla (curso de Arquitetura e Urbanismo); Anie Elise Bello Fallani e Sandra Eli Aparecida Gritti (curso de Direito); Patrícia Príncepe, Renata de Godoy Torso, Tatiana Moura Garcia Paulo, Laís Jaqueta Bernardes, Lívia Simões e Solange Aparecida Marcondes do Amaral (curso de mencionados.

\section{As assessorias interdisciplinares}

Em geral, todo processo de regularização fundiária e melhoramento de habitação está permeado por prazos dilatados e relativamente onerosos (Bastidas, 2003). Nossa intervenção não se afastou destas determinantes, pois grande maioria das propriedades foram levantadas em Itatiba e Amparo e fornecidos os projetos de melhoras construtivas em Itatiba. Porém, em função de diversos entraves, a totalidade não foi atingida.

A seguir, apresentam-se os dados levantados e analisados que permitem a compreensão dos estágios atuais de cada uma das fases arroladas. Destarte, organizaram-se as informações na mesma seqüência dos três eixos estruturadores desta intervenção sendo nomeadas a partir deste momento como assessorias: urbanística, jurídica e sócio-educativa.

\section{Assessoria urbanística}

Para os projetos CASA e HABITAMPARO esta fase teve dois momentos concomitantemente desenvolvidos, a saber: a) o levantamento dos dados demográficos, socioeconômicos e de propriedade dos imóveis; e b) o levantamento arquitetônico das residências e dos lotes localizados na área de estudo. A maioria das situações que se pretende explicitar está baseada na interpretação das percepções do cotidiano dos moradores recolhidas em forma de depoimentos pontuais (entrevistas) e da mensuração dos dados e avaliações das casas.

Quanto ao levantamento dos dados demográficos, o primeiro item abordado diz respeito às cidades de origem. Verifica-se que os lugares de procedência das pessoas componentes dos núcleos familiares são heterogêneos. Os assentamentos possem uma grande parte de migrantes dos esta-

Pedagogia). 
dos de Minas Gerais e São Paulo, especialmente, das cidades contíguas aos municípios de Itatiba e Amparo como: Morungaba, Atibaia, Bragança Paulista, Jundiaí e Pedreira. Como circunstância paradoxal conferiu-se que no Bairro Jaguari de Amparo são poucas as pessoas nascidas no município.

Em contradição à peculiar ocupação dos assentamentos subnormais por populações predominantemente infantis, nestes casos ressaltamos que são majoritárias as faixas etárias dos indivíduos com idade acima dos 12 anos. Estas representam praticamente o $50 \%$ da população total dos loteamentos. A menor concentração de pessoas encontra-se na faixa das pessoas acima de 60 anos.

Em relação à atividade econômica da população ativa, a maioria dos chefes de família possui vínculo empregatício com registro em carteira e o desenvolvimento de outras atividades como pertencentes ao mercado de autônomos, "bicos", etc. Há uma parcela pequena de moradores que recebe aposentadoria. Para a época dos levantamentos existia uma taxa de desemprego em São Paulo que oscilava entre $5,0 \%$ a $7,0 \%$ e outra. Nos assentamentos está taxa era um pouco maior em vista da baixa escolaridade dos moradores.

Dentro dos assentamentos foi identificado um leque copioso de ofícios e profissões inseridas sempre nos diversos setores da economia primária. Cabe salientar que, os empregos associados a atividades como: agricultura, construção, comércio e iniciativas públicas e privadas, a maioria destes (aproximadamente 65\%) estão concentrados em Itatiba e Morungaba. A renda mensal familiar oscila entre 1,5 a 2,0 salários mínimos legais vigentes. Tratando-se de um assentamento irregular, esta última situação não pode ser catalogada como atípica, pois, em muitas ocasiões foi revelada a renda coletiva do núcleo. Isto é, a somatória dos salários dos integrantes da família.

Por outra parte, quanto ao levantamento arqui- tetônico podem ser apresentadas as seguintes considerações. Por motivos procedimentais os assentamentos de Itatiba e Amparo foram divididos em 29 e 13 quarteirões de acordo com nomenclatura alfabética e a subdivisão interna foi numérica. Este procedimento precedeu a visitação das residências e permitiu conferir in loco os levantamentos topográficos fornecidos pelas Prefeituras.

O número de lotes que consta no cadastro da Prefeitura de Itatiba é de 1745 no bairro San Francisco, já no Bairro Jaguari de Amparo existem 342 propriedades. No San Francisco apenas o 7,5\% dos lotes estão vazios, que demonstra uma situação de consolidação e alta densidade. O quadro do Jaguari mostra um esvaziamento do lotes quase três vezes maior. Em ambos os casos, os loteamentos estavam submetidos a um processo paulatino de desmembramento espacial da propriedade. Isto é, as unidades não conservam seu tamanho inicial prejudicando ainda mais suas desfavoráveis condições originais.

Por outra parte, em Itatiba o bairro San Francisco é provido de infra-estrutura completa: rede de água e esgoto, iluminação, ruas asfaltadas, coleta de lixo, transporte urbano e equipamentos tais como escola, posto de saúde, centro comunitário. A situação é diferente no bairro Jaguari, onde comparecem a maioria dos problemas das favelas, especialmente no que diz respeito à cobertura de serviços públicos e infra-estrutura. A incipiência material das casas e de poucas áreas de lazer; ou quando existem não tem manutenção, são registradas nos dois assentamentos estudados. Unicamente em casos rarefeitos existem condições extremas de adversa habitabilidade e confinamento de pessoas.

Nos bairros, o espaço que permite a interação social é a rua. A inexistência de um sistema articulado de espaços públicos (parques, praças e calçadas) com atributos que favoreçam a integração dos moradores somada à tênue definição 
dos limites reais dos lotes com relação aos espaços públicos possibilitou a "privatização" paulatina de algumas áreas do loteamento. Os casos mais destacados surgem nas esquinas e em setores adjacentes às áreas de preservação (rio). Esta situação evidencia até que ponto o direito individual fragilizou o direito coletivo.

Os dois assentamentos são predominantemente residenciais, sendo que também são identificáveis outros tipos de usos e funções de forma disseminada e esporádica. Entre estes prevalecem, em ordem decrescente de hierarquia, as propriedades com os seguintes usos: comercial, religioso, educativo e atendimento social e de saúde. Do ponto de vista morfológico, no loteamento identificaramse vários tipos de configurações as mais freqüentes são as casas térreas e construções de um andar.

Em função da grande quantia de edificações no bairro San Francisco foi feito um recorte quantitativo, isto é, tomou-se uma amostra de 75 casas. Este obedeceu ao interesse por participar e teve certa aleatoriedade. A abordagem das avaliações das unidades habitacionais do San Francisco foi alicerçada na avaliação pósocupação (Abiko; Ornstein, 2002) Esta esteve baseada em certos atributos que foram contemplados na entrevista: a) morfologia, distribuição e dimensionamento das casas; b) condições higiênicas dos espaços; c) conforto ambiental (térmico, luminoso e acústico); d) instalações e equipamentos instalados; e e) matérias e características técnico construtivas.

Além disso, foram adotados alguns critérios de classificação das habitações. Quanto ao seu grau de habitabilidade para verificar as deficiências nos itens mais importantes da construção e definir se a construção era: precária, insatisfatória ou suficiente. Evidenciou-se que o $64 \%$ pertence ao grupo mais frágil, na seqüência o $20 \%$ estão alocadas no patamar de insatisfatórias e 0 privilegiado $12 \%$ reúne as suficientes. Também foi feita uma categorização, associada à desoneração de impostos, com relação às áreas construídas para determinar a sistematização em três faixas: até $70 \mathrm{~m}^{2}$ (74,67\% de edificações), entre 70 e 90 $\mathrm{m}^{2}\left(13,33 \%\right.$ de edificações) e acima de $90 \mathrm{~m}^{2}$.

Pelo diagnóstico de habitabilidade das edificações constatou-se que, grande parte das moradias do projeto CASA tem problemas em vários dos itens analisados. A priori, a principal questão esteve relacionada a que as edificações encontram-se implantadas em lotes com declividade acentuada e as soluções dos proprietários, com estruturas mal dimensionadas, não foram as adequadas. No projeto HABITAMPARO está abordagem da habitabilidade, por questões operacionais, foi tangencialmente abordada.

Finalmente, nesta etapa de assessoria urbanística, foram desenvolvidas questões referidas a: a) correção e atualização de informações dos levantamentos, dados cadastrais e atualização do levantamento fotográfico; b) elaboração dos memoriais descritivos e propostas de urbanização do projeto visando a melhoria da infra-estrutura do bairro e adequação do loteamento à legislação vigente (considerando também a destinação de áreas livres, institucionais e de lazer); e c) elaboração do projeto para a preservação das APAS (áreas de proteção ambiental), APP'S (áreas de preservação permanente), recuperação da mata ciliar existente no loteamento e proposta de um parque linear como intervenção paisagísticas. $O$ item c apenas vale para o projeto HABITAMPARO, pois no bairro San Francisco não existe proximidade com um tipo de cenário similar para salvaguardar.

\section{Assessoria jurídica}

Esta etapa esteve atrelada à assessoria urbana, portanto, subsidiou-se no processamento da das informações coletadas. No projeto CASA, o grau de aprofundamento desta experiência esteve mais 
focada em questões de escopo instrumental. Da amostragem de 74 edificações observou-se que 55 edificações tinham registro; sendo que em $30,90 \%$ ainda permanecia em nome da empresa loteadora e em $69,1 \%$ constava de terceiros adquirentes. Embora, em nenhum dos casos tenha sido constatada averbação de construção, todos os lotes tiveram implantada uma edificação. Observouse uma enorme heterogeneidade de situações dominiais dos atuais ocupantes dos imóveis, que não podem ser desconsideradas, devendo se admitir como comprovação da propriedade não unicamente a certidão de propriedade, mas também as diversas formas documentais portadas pelos ocupantes.

No projeto HABITAMPARO foi recolhida a documentação de mais da metade dos imóveis do bairro e determinadas várias classificações que subsidiariam a parte da legalização das propriedades. Verificou-se que até $65 \%$ possuem título de propriedade sem vinculo com documento original emitido pelo loteador, $35 \%$ tem o titulo referido com vínculo e o restante tem um título emitido em nome do titular pelo loteador original. Com relação ao tamanho da propriedade 55\% possuem área de até $250 \mathrm{~m}^{2}$ e $45 \%$ área maior que essa cifra. Aplicando a variável tempo de posse, o quadro revela que o $50 \%$ exerce a posse mansa e pacífica há mais de 10 anos, 19\% exercem a posse entre 5 a 10 anos, $26 \%$ exercem a posse há menos de 5 anos e $5 \%$ não estavam em situação indefinida, pois o não era possível possuir o tempo de exercício de posse definido baseado nos documentos apresentados.

O cruzamento dos anteriores dados permitiu identificar que tipo de usucapião individual era possível utilizar nos processos perante a justiça mbalista; Rolnik, 1997). Inferiu-se que $60 \%$ das propriedades estão inscritas na usucapião urbano, pois tem lotes menores que $250 \mathrm{~m}^{2}$. Quase um terço está amparado pela usucapião extraordinário em decorrência da posse a mais de 15 anos e que o usucapião ordinário seria aplicável no resto dos casos, já que ostentam escrituras de parte ideal acordada.

A condução das ações de caráter individual foi viabilizada pela criação de um "kit judicial". Esta pasta de documentos entregues à Prefeitura reúne: 1. Caracterização do Possuidor e do Imóvel; 2. Cópias dos Documentos Coletados; 3. Histórico do Loteamento; 4. Carta de Anuência da Prefeitura do Município de Amparo; 5. Cartas de Anuência dos Confrontantes; 6. Memorial Descritivo do Lote; 7. Planta Cadastral do Lote; 8. Cópia da Lei Municipal № 3.321/2007 - Instituição da Zona Especial de Interesse Social - Zeis da NUP Do Jaguary (NUP-6A); 9. Cópia da Art no 92221220080343537/2008 (CREA 060177512-0) e Art № 92221220080367320/2008 (CREA 5060726538).

No processo foram detectados certos descompassos, que não são sui generis, devido às várias dificuldades advindas da natureza do trabalho de extensão. Se, por uma parte, durante a execução a receptividade e os resultados parciais foram satisfatórios, não é possível negligenciar que prazos mais dilatados interferiram diretamente nas tarefas planejadas. Mas, por serem questões pontuais não serão elencadas, apenas resta afirmar que em todas as circunstancias cada problema teve a previsão de uma ação para mediar na solução ou equacionamento.

É importante enfatizar que a regularização fundiária e o melhoramento de habitações têm desdobramentos imprevisíveis e irrestritos. Assim, os números descritos apresentam informações fundamentais para as futuras ações administrativas e legislativas a serem desenvolvidas pelas Prefeituras, visando a aproximação à cidadania. Entretanto, cabe refletir se, por exemplo, as famílias que não foram contempladas pelos projetos CASA e HABITAMPARO, em função de questões pon- 
tuais, e as prefeituras permitirão a continuidade do processo de regularização fundiária? Além disso, é inadiável a criação de instrumentos práticos para garantir a permanência da comunidade para que não sejam preteridos pela especulação imobiliária.

\section{Assessoria Sócio-educativa}

Acredita-se que esta fase permitirá a concretização do projeto de legalização nos planos sociais, educativos, ambientais, etc. No quesito da escolaridade do núcleo familiar detecta-se que tanto no bairro San Francisco, quanto no Jaguari pelo menos um terço da população possui o primeiro grau incompleto. Nesta ordem de idéias, as pessoas que tem como formação final o segundo grau representam menos de um quarto da população. A taxa media de analfabetismo das duas comunidades é relativamente baixa (aproximadamente $4,5 \%$ ), se comparada à média do Brasil que em 2009 estava em $9,8 \%$.

No caso do bairro San Francisco, em função do contingente populacional (8000 pessoas) foram propostas duas ações. Um curso de capacitação do Canteiro-Escola que teve como finalidade a qualificação de mão-de-obra, visando fornecer aos moradores os conhecimentos necessários para aplicar melhorias da própria moradia. Este curso esteve composto de dois níveis: a) Básico (Módulo 1): formação geral esteve estruturado numa revisão de matemática aplicada à construção civil e um mini-curso sobre o planejamento da economia familiar; e b) Profissional (Módulos de 2 a 6): que propendeu pela formação profissionalizante em atividades que envolvem os fundamentos da construção civil. Esta parte envolveu diversas especialidades, a saber: leitura de plantas, fundação, execução de alvenaria, execução de telhados, execução de reboco, assentamento de azulejos e pisos, execução das instalações elétricas, hidráulicas e esgotamento sanitário. O Curso, desenvolvido em módulos, teve boa acolhida e previu a entrega de um certificado de conclusão ao aluno que completou o módulo básico e um módulo profissionalizante.

A outra ação prevista foi o assessoramento técnico para formação de uma cooperativa dos moradores do bairro. A cooperativa visa criar condições de organização entre os moradores (mutirões, a obtenção de financiamento para a aquisição de material empregado nas obras, etc.). Além disso, será possível uma capacitação nos diversos níveis, articulando uma organização social de trabalho dos componentes da cooperativa. A primeira obra neste sentido foi a promoção de reuniões com moradores interessados.

De modo análogo, no Bairro Jaguari (990 habitantes) adiantou-se a articulação de ações que procuraram: o trabalho junto à Associação de Moradores e a qualificação da comunidade.

O robustecimento da Associação de Moradores previu dissímeis etapas. Em primeiro lugar verificou-se a situação de regularidade e identificação da necessidade de viabilizar para sua regularização. Foram criadas comissões de trabalho, para o acompanhamento do processo. O diagnóstico desta circunstância terminou na regularização da Associação perante os órgãos públicos e cartório. A partir deste ponto, alavancou-se a efetiva participação dos moradores na associação e nos processos de sua representação (foram delineadas as diretrizes para a realização da Assembléia para eleição, aprovação de novo estatuto, julgamento das contas das diretorias, etc.), em fim envolvimento nos processos sucessórios e administrativos da Associação. Este passo foi crucial porque também subsidiou o encaminhamento de ações junto aos órgãos competentes e a resposta da defensoria pública sobre sua participação no patrocínio dos processos individuais de regularização fundiária encaminhados.

Algumas ações que conjugam a organização comunitária e educação foram esboçadas. Destacase a educação não-formal direcionada a organi- 
zações sociais que fornece procedimentos para a coleta das memórias dos moradores do Jaguarí. Simultaneamente salientou-se a formação de multiplicadores para a implementação do programa "Direitos e Deveres", com a finalidade de que as atividades da associação possam acontecer de forma constante e democrática.

Por outra parte, com escopo educativo-ambiental foram implementadas diversas oficinas de: reciclagem, pintura, informática, etc. (Figura 6). Estas foram ministradas pelos estagiários e/ou professores. O público que freqüentou estas atividades foi geralmente a população infantil do bairro Jaguari e áreas adjacentes. As aulas tiveram o intuito de caracterizar alternativas de geração de renda e educa-ção ambiental, direta ou indireta, para as pessoas do bairro.

$\mathrm{Na}$ educação ambiental foram implementadas as seguintes ações: a) Reciclagem do lixo; b) Oficina de mosaico a partir do lixo recolhido; c) Oficina de fabricação de tinta à base de terra. As três oficinas partem do principio de aproveitar o material usado originário do próprio local, isto é, o bairro Jaguari. Os trabalhos desenvolvidos pelos alunos foram executados nas instalações da Associação de Moradores.

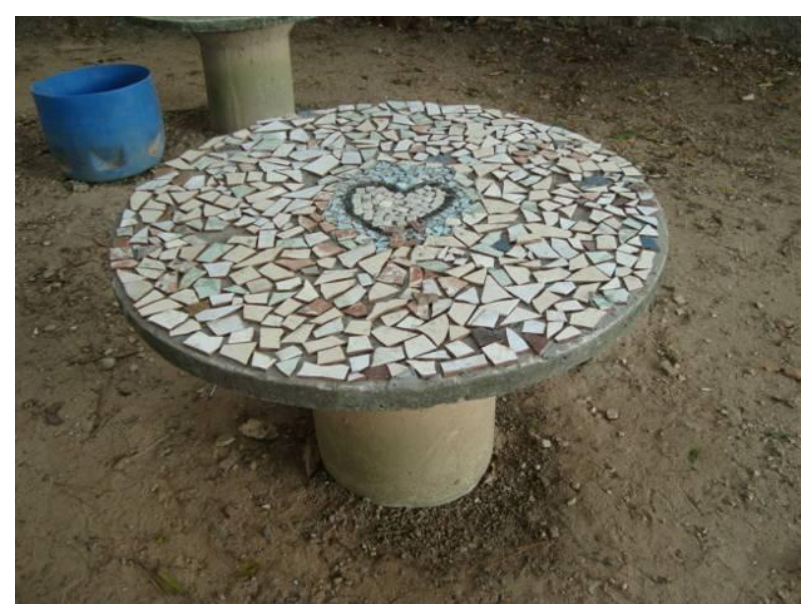

Figura 6a: Resultado das atividades desenvolvidas nas oficinas. Fonte: Arquivo CEUr (Universidade São Francisco).

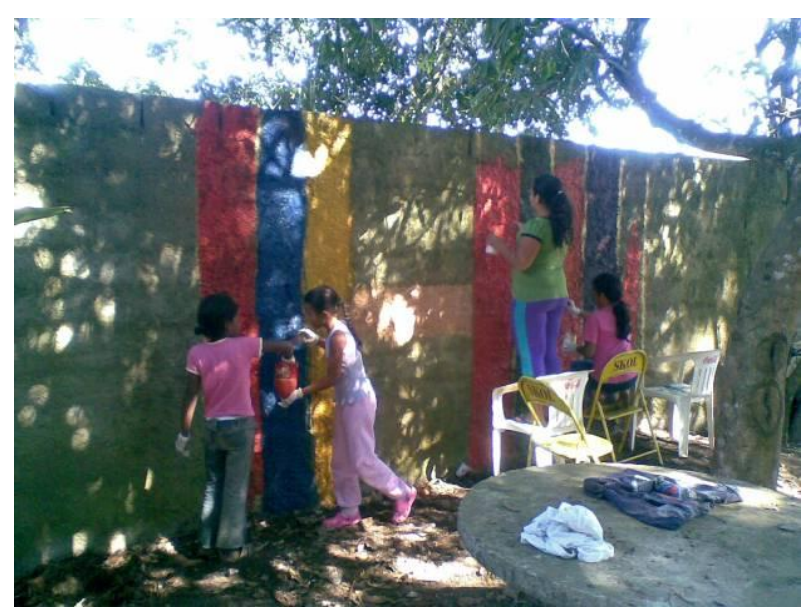

Figura 6b: Resultado das atividades desenvolvidas nas oficinas. Fonte: Arquivo CEUr (Universidade São Francisco).

Quanto às oficinas para capacitação de moradores foi ministrado um curso de inclusão digital. A Universidade São Francisco viabilizou a parte operativa desta oficina, pois doou alguns computadores e equipamentos. A organização do material para este mini-curso foi formatada como um curso básico em informática. É importante salientar que, em face da finalização do projeto alguns moradores, se dispuseram a dar continuidade ao processo de inclusão digital para os próximos interessados.

Tradicionalmente, a assessoria sócio-educativa tem uma complexidade expressiva e certa defasagem com relação às outras assessorias. Mas é considerada essencial neste tipo de projetos de extensão, pois os processos de regularização fundiária e melhoria das edificações, entendidos como propostas que trazem segurança da posse da terra e habitabilidade, não procuram apenas sua concretização material, mas a criação de um conjunto de estratégias de desenvolvimento e independência.

Nos assentamentos, objeto de estudo desta intervenção, é possível elucidar que foi fundamental a participação das comunidades envolvidas, em especial Amparo, pois são as principalmente afetadas e auferirão os benefícios e as obrigações junto à sociedade. Quando as comunidades conhecem e se integram aos processos, como primeiras interessadas, além de saber as limitações de um re- 
lativamente longo e entravado processo judicial constroem elos para a plausível articulação de ações que propendam pela melhoria de qualidade de vida em outras áreas.

O projeto CASA prezou no sentido de prover regularização tanto construtiva, quanto fundiária. A concretização da transferência legal da titularidade dos lotes amplia a obtenção de prerrogativas e incorporação de direitos de cidadão. Embora o projeto tenha planejado objetivos ambiciosos, este não conseguiu sua efetivação total, isto é, a entrega da documentação para obter a titularidade do imóvel. Nesse caso, as principais circunstâncias que obstaram os objetivos foram: a) a falta de interesse do governo de Itatiba em firmar outras parcerias junto aos órgãos pertinentes para finalizar o processo legal; b) o incipiente envolvimento da comunidade nas reuniões e a inexistência de uma Associação de Moradores organizada e mobilizada.

O projeto HABITAMPARO obteve avanços significativos em relação ao projeto CASA. Uma das explicações para este ocorrência surge a partir da ampliação da equipe técnica, pois além dos cursos de Arquitetura e Urbanismo e Direito, a inclusão da Pedagogia proveu um maior grau de compromisso da comunidade, identificação e apropriação do trabalho executado. A totalidade dos produtos foi entregue individualmente a cada morador e à Prefeitura Municipal de Amparo para que sejam encaminhados ao Poder Judiciário. A estreita relação comunidade/Universidade possibilitou a constante troca de informações. Esta foi decantada pela constante fiscalização da comunidade e da Prefeitura, através de reuniões periódicas entre todos os atores submersos no processo.

Os resultados obtidos permitem inferir uma metodologia que subsidia conceitualmente os processos de regularização fundiária e melhoramento de habitação social. No Brasil, a questão habitacional está atrelada à questão fundiária, pois é impossí- vel mencionar uma sem mencionar a outra e viceversa. Em hipótese, o problema da falta de moradia seria resolvido considerando conjuntamente estas variáveis.

Para encerrar o tópico das consultorias interdisciplinares é importante asseverar que apelando a todos os tipos de assessorias explanadas para a regularização fundiária dos assentamentos e melhoramento das edificações, as cidades de Itatiba e Amparo viabilizaram a recomposição da malha urbana. Preliminarmente, estes instrumentos possibilitaram a circunscrição de ocupações de unidades habitacionais que não são compatíveis com áreas de preservação, de mananciais, de uso comum do povo e áreas de risco. Mas, parte dessa discussão será ampliada no item derradeiro deste texto.

\section{Considerações finais}

Não obstante as cidades menores não sofram das dificuldades dos grandes centros urbanos, nestes conglomerados também comparecem múltiplas nuances que representam entraves no seu desenvolvimento. Entretanto, não são apenas de natureza física, mas também tem escopo governamental. $\mathrm{Na}$ prática, isto significa falta de diretrizes institucionais capazes de nortear seu progresso ${ }^{8}$. A atuação da Universidade São Francisco que delineou as parcerias que resultaram nos projetos de extensão CASA e HABITAMPARO tentaram revertem essa lógica e reergueram as balizas para melhorar a qualidade de vida dos moradores dos bairros analisados.

Vale a pena salientar que o tipo de precariedade, especialmente construtiva ${ }^{9}$, encontrada em Itatiba

\footnotetext{
8 Este problemática se considerada isolada do contexto não teria graves repercussões, mas quando vista à luz de incertezas operacionais e financeiras, atreladas à dimensão dos municípios ganha proporções incomensuráveis.

${ }^{9}$ Importante acrescentar que a questão habitacional no Brasil apresenta deficiências não apenas no que toca a políticas habitacionais efetivas, mas também em relação à oferta de tecnologias. Nesta área ainda impera o processo artesanal de construção, de qualidade questionável e custos altos. Verifica-se também que o desperdício é atestado pela quantidade de ma-
} 
e Amparo difere da pobreza de São Paulo e Campinas ${ }^{10}$. Alguns estudos urbanos e demográficos recentes apontam que o crescimento das grandes cidades também esta sendo dissolvido não apenas nas áreas metropolitanas, mas em áreas adjacentes. Nesta assertiva radica a importância dos pequenos núcleos urbanos para responder ao problema habitacional e de regularização fundiária.

Em síntese, a análise explanada dos dois projetos revela que existem certos descompassos que merecem uma elucidação mais aprimorada. Surge a inquietação de porque, sendo dois projetos que possuem o mesmo escopo e finalidades semelhantes um dos supracitados mostrou resultados mais expressivos. Para esclarecer este ponto é necessário apelar a esclarecimentos em três direções: a Interdisciplinaridade, a consolidação da relação com a comunidade e as parcerias interinstitucionais.

As parcerias interinstitucionais entre as Prefeituras de Itatiba e Amparo e a Universidade São Francisco (CEUr) mostram a função social das entidades educativas. Acredita-se que deste prisma, o conhecimento não fica restrito ao ambiente universitário, mas serve para alavancar processos de transformação no intuito de permitir a inclusão sócioespacial, isto é, recuperar o autêntico direito da cidade para todos. Mas, ao mesmo tempo, não é possível negligenciar a atuação dos governos locais e a participação dos habitantes dos assentamentos. Todos conjugados são fatores peremptórios na solução de problemas associados às questões de Habitação de Interesse Social no Brasil. Grosso modo, a regularização fundiária não pode

téria-prima que sai da obra sob forma de entulho, chegando a representar o 30\% na execução.

10 Trata-se de um gênero de escassez de recursos menos concentrado, pois nas cidades que ostentam maior densidade os contrastes resultam mais gritantes. Mas, esta afirmação não significa a negação das outras feições identificadas em assentamentos subnormais. De modo contraposto, é possível afirmar que, no sentido da segregação sócio-espacial, estamos lidando com nuances análogas. receber o peso de ser considerada uma política habitacional. Isto, porque uma aceitação implícita da sociedade deste tipo de ações, além de gerar precedentes desvirtuados, permite o robustecimento da criação de um círculo vicioso. No âmbito brasileiro também se deve focar a atenção em que qualquer forma de legalização obriga paralelamente à articulação de ações com as outras políticas sociais e urbanas locais e regionais como: melhorias na unidade habitacional, espaço publico, dotação de postos de saúde, educação cultura e esportes, canalização de córregos, complementação de redes infra-estrutura, programas de geração de emprego e renda, etc. Na mesma perspectiva dessas últimas ações deve ser possível propiciar pela disseminação das informações concernentes à legislação, a capacitação de lideranças e a consolidação de organizações comunitárias.

Finalmente, ressaltemos que mesmo tendo conhecimento de que qualquer investimento de recursos das administrações municipais, estaduais ou federais é precedido por um processo de legalização dos assentamentos, esse não pode ser paliativo, nem fruto de interesses políticos. Os programas implementados, sobretudo, devem ser coerentes com a Constituição brasileira com a finalidade de garantir os direitos fundamentais dos cidadãos, em especial, o direito à moradia.

\section{Referências}

ABIKO, Alex K.; ORNSTEIN, Sheila W. Inserção Urbana e Avaliação Pós-Ocupação (APO) da Habitação de Interesse Social. São Paulo: FAU/USP, 2002.

ALFONSIN, Betânia. Direito à moradia: instrumentos e experiências de regularização fundiária nas cidades brasileiras. Rio de Janeiro: IPPUR / FASE, 1997.

ALFONSIN, Betânia. O significado do estatuto da cidade para os processos de regularização fun- 
diária no Brasil. In FERNANDES, Edésio e AL-

FONSIN, Betânia. Evolução do direito urbanístico. Belo Horizonte: PUC Minas Virtual, 2006.

BASTIDAS, Jairo, et al. Estruturando a Estrutural: estudo de caso de uma favela na cidade de Brasília. Trabalho da disciplina Desenho urbano II.

Curso de Pós-graduação em Arquitetura e Urbanismo da Universidade de Brasília, 2003.

CYMBALISTA, Raquel e ROLNIK, Renato. Instrumentos Urbanísticos contra a exclusão social. Revista Pólis, 1997, № 29, p. 43-55.

FERNANDES, Edésio. Direito e urbanização no Brasil. In FERNANDES, Edesio (org.). Direito Urbanístico. São Paulo: Livraria Del Rey Editora, 1998.

FERNANDES, Edésio. Do Código Civil ao Estatuto da Cidade algumas notas sobre a trajetória do Direito Urbanístico no Brasil. URBANA, 2002, vol.7, no 30, p. 43-59.

KOHLSDORF, Maria E. A apreensão da forma da cidade. Brasília: Editora Universidade de Brasília, 1996.

MARICATO, Erminia. Metrópole na periferia do capitalismo: ilegalidade, desigualdade e violên- cia. São Paulo: Hucitec, 1996.

PEREIRA, R.; LOEWEN, A.B.; RIBEIRO, C. Projeto Casa: Assessoria Técnica para Recuperação e Adequação de Habitações para População de Baixa Renda. I SEHTHAB - Seminário de história e de tecnologia da habitação. Pesquisa em Habitação: Desafios e Perspectivas. Itatiba: Ed. Universidade São Francisco, 2008.

ROLNIK, Raquel. A cidade e a lei-legislação, política urbana e territórios na cidade de São Paulo. FAPESP, São Paulo: Studio Nobel, 1997.

ROLNIK, Raquel, et al. Plano Diretor participativo. Guia para elaboração pelos municípios e cidadãos. Brasília: Ministério das Cidades, 2004.

\section{Cita del artículo}

FRICKE, Glacir T.; BASTIDAS, Jairo; QUAGLIA, Sergio. Algumas experiências acadêmicas em habitação de interesse social na região sudeste do Brasil: regularização fundiária em municípios entre as regiões metropolitanas de Campinas e São Paulo. Hábitat y Sociedad, 2010, no 1, p. 133-149. <www.habitatysociedad.us.es>.

http://dx.doi.org/10.12795/HabitatySociedad.2010.i1.09 